\title{
Prevalence of Obesity Among Adults, by Household Income and Education — United States, 2011-2014
}

\author{
Cynthia L. Ogden, $\mathrm{PhD}^{1}$; Tala H. Fakhouri, $\mathrm{PhD}^{1}$; Margaret D. Carroll, MSPH${ }^{1}$; Craig M. Hales, MD ${ }^{1}$; Cheryl D. Fryar, MSPH${ }^{1}$;
} Xianfen Li, MS ${ }^{2}$; David S. Freedman, $\mathrm{PhD}^{3}$

Studies have suggested that obesity prevalence varies by income and educational level, although patterns might differ between high-income and low-income countries (1-3). Previous analyses of U.S. data have shown that the prevalence of obesity varied by income and education, but results were not consistent by sex and race/Hispanic origin (4). Using data from the National Health and Nutrition Examination Survey (NHANES), CDC analyzed obesity prevalence among adults (aged $\geq 20$ years) by three levels of household income, based on percentage $(\leq 130 \%,>130 \%$ to $\leq 350 \%$, and $>350 \%)$ of the federal poverty level (FPL) and individual education level (high school graduate or less, some college, and college graduate). During 2011-2014, the age-adjusted prevalence of obesity among adults was lower in the highest income group $(31.2 \%)$ than the other groups ( $40.8 \%$ [ $>130 \%$ to $\leq 350 \%]$ and $39.0 \%[\leq 130 \%])$. The age-adjusted prevalence of obesity among college graduates was lower $(27.8 \%)$ than among those with some college $(40.6 \%)$ and those who were high school graduates or less $(40.0 \%)$. The patterns were not consistent across all sex and racial/Hispanic origin subgroups. Continued progress is needed to achieve the Healthy People 2020 targets of reducing age-adjusted obesity prevalence to $<30.5 \%$ and reducing disparities (5).

NHANES is a biannual cross-sectional survey designed to monitor the health and nutritional status of the civilian noninstitutionalized U.S. population (G). The survey consists of in-home interviews and standardized physical examinations conducted in mobile examination centers. During the physical examination, standardized measurements of weight and height were obtained. Body mass index (BMI) was calculated as weight in kilograms divided by height in meters squared. Obesity was defined as a BMI $\geq 30 \mathrm{~kg} / \mathrm{m}^{2}$. The NHANES sample is selected through a complex, multistage probability design. Participants self-reported race/Hispanic origin, and were divided into five categories: non-Hispanic white, nonHispanic black, non-Hispanic Asian, Hispanic and "other." During 2011-2014, non-Hispanic black, non-Hispanic Asian, and Hispanic persons, among other groups, were oversampled. A total of 308 non-Hispanic persons reporting other races or more than one race were placed in an "other" category, and their data were included in the overall results. The NHANES examination response rate for adults aged $\geq 20$ years was $64.5 \%$ in the 2011-2012 survey and 63.7\% in the 2013-2014 survey.

Household income was categorized using FPL information, which accounts for inflation and family size (https://aspe. hhs.gov/prior-hhs-poverty-guidelines-and-federal-registerreferences); income levels were designated as $\leq 130 \%,>130 \%$

\section{INSIDE}

1374 Prevalence and Disparities in Tobacco Product Use Among American Indians/Alaska Natives - United States, 2010-2015

1379 CDC Grand Rounds: National Amyotrophic Lateral Sclerosis (ALS) Registry Impact, Challenges, and Future Directions

1383 Update: Providing Quality Family Planning Services - Recommendations from CDC and the U.S. Office of Population Affairs, 2017

1386 Notes from the Field: Use of Asynchronous Video Directly Observed Therapy for Treatment of Tuberculosis and Latent Tuberculosis Infection in a Long-Term-Care Facility — Puerto Rico, 2016-2017

1389 QuickStats

Continuing Education examination available at https://www.cdc.gov/mmwr/cme/conted_info.html\#weekly.

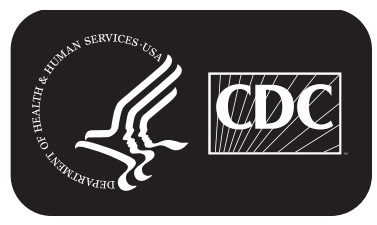

U.S. Department of Health and Human Services Centers for Disease Control and Prevention 
to $\leq 350 \%$, and $>350 \%$ of FPL. The cut point for participation in the Supplemental Nutrition Assistance Program is 130\% of the poverty level, and $350 \%$ provides relatively equal sample sizes for each of the three income groups. Education was categorized as high school graduate or less, some college, and college graduate.

All estimates were adjusted to account for the complex survey design, including examination sample weights. Estimates were age-adjusted to the 2000 projected U.S. Census population using the age groups $20-39,40-59$, and $\geq 60$ years. Confidence intervals for estimates were calculated using the Wald method. Differences between income and education groups were tested using a two-sided, univariate t-statistic, with statistical significance defined as a p-value of $<0.05$. Temporal trends from 1999-2002 to 2011-2014 were analyzed using orthogonal contrasts and 2-year survey cycles. Pregnant women (122) and participants with missing weight or height (571) were excluded, resulting in a total sample size of 10,636 for the period 2011-2014. For estimates by FPL, an additional 851 participants were excluded because of missing FPL data, and for estimates by education, eight participants were excluded because information on education was missing.

During 2011-2014, the age-adjusted prevalence of obesity was $38.3 \%$ among women and $34.3 \%$ among men (Table). The prevalence of obesity was $34.5 \%$ among non-Hispanic white adults, $48.1 \%$ among non-Hispanic black adults, $11.7 \%$ among non-Hispanic Asian adults, and $42.5 \%$ among Hispanic adults.
Among women, prevalence was lower in the highest income group $(29.7 \%)$ than in the middle $(42.9 \%)$ and lowest (45.2\%) income groups. This pattern was observed among non-Hispanic white, non-Hispanic Asian, and Hispanic women, but it was only significant for white women. Among non-Hispanic black women, there was no difference in obesity prevalence among the income groups.

Among men, the prevalence of obesity was lower in both the lowest $(31.5 \%)$ and highest $(32.6 \%)$ income groups compared with the middle-income group (38.5\%). This pattern was seen among both non-Hispanic white and Hispanic men, although among non-Hispanic white men, the difference between the highest-income and middle-income groups was not statistically significant. Among non-Hispanic black men, obesity prevalence was higher in the highest income group $(42.7 \%)$ than in the lowest income group (33.8\%). There was no difference in obesity prevalence by income among non-Hispanic Asian men.

In 2011-2014, the prevalence of obesity was lower among women and men who were college graduates (27.8\% [women], $27.9 \%[\mathrm{men}])$ than among women and men with some college $(41.2 \%, 40.0 \%)$ and women and men who were high school graduates or less $(45.3 \%, 35.5 \%)$. By race/Hispanic origin, the same pattern was seen among non-Hispanic white, non-Hispanic black, and Hispanic women, and also among non-Hispanic white men, although the differences were not all statistically significant. Although the difference was not statistically significant among non-Hispanic black men, obesity prevalence increased with educational attainment. Among

The MMWR series of publications is published by the Center for Surveillance, Epidemiology, and Laboratory Services, Centers for Disease Control and Prevention (CDC), U.S. Department of Health and Human Services, Atlanta, GA 30329-4027.

Suggested citation: [Author names; first three, then et al., if more than six.] [Report title]. MMWR Morb Mortal Wkly Rep 2017;66:[inclusive page numbers].

\section{Centers for Disease Control and Prevention Brenda Fitzgerald, MD, Director \\ William R. Mac Kenzie, MD, Acting Associate Director for Science Joanne Cono, MD, ScM, Director, Office of Science Quality \\ Chesley L. Richards, MD, MPH, Deputy Director for Public Health Scientific Services \\ Michael F. Iademarco, MD, MPH, Director, Center for Surveillance, Epidemiology, and Laboratory Services}

MMWR Editorial and Production Staff (Weekly)

Sonja A. Rasmussen, MD, MS, Editor-in-Chief

Charlotte K. Kent, PhD, MPH, Executive Editor Jacqueline Gindler, MD, Editor

Teresa F. Rutledge, Managing Editor

Douglas W. Weatherwax, Lead Technical Writer-Editor

Soumya Dunworth, PhD, Kristy Gerdes, MPH, Teresa M. Hood, MS, Technical Writer-Editors
Martha F. Boyd, Lead Visual Information Specialist

Maureen A. Leahy, Julia C. Martinroe, Stephen R. Spriggs, Tong Yang, Visual Information Specialists

Quang M. Doan, MBA, Phyllis H. King,

Paul D. Maitland, Terraye M. Starr, Moua Yang, Information Technology Specialists
MMWR Editorial Board

Timothy F. Jones, MD, Chairman

Matthew L. Boulton, MD, MPH Virginia A. Caine, MD

Katherine Lyon Daniel, PhD

Jonathan E. Fielding, MD, MPH, MBA

David W. Fleming, MD
William E. Halperin, MD, DrPH, MPH

King K. Holmes, MD, PhD

Robin Ikeda, MD, MPH

Rima F. Khabbaz, MD

Phyllis Meadows, PhD, MSN, RN

Jewel Mullen, MD, MPH, MPA
Jeff Niederdeppe, PhD

Patricia Quinlisk, MD, MPH

Patrick L. Remington, MD, MPH Carlos Roig, MS, MA

William L. Roper, MD, MPH

William Schaffner, MD 
Morbidity and Mortality Weekly Report

TABLE. Prevalence of obesity among adults, ${ }^{*}$ by race/Hispanic origin, sex, household income (percentage of FPL), and education — National Health and Nutrition Examination Survey, 2011-2014

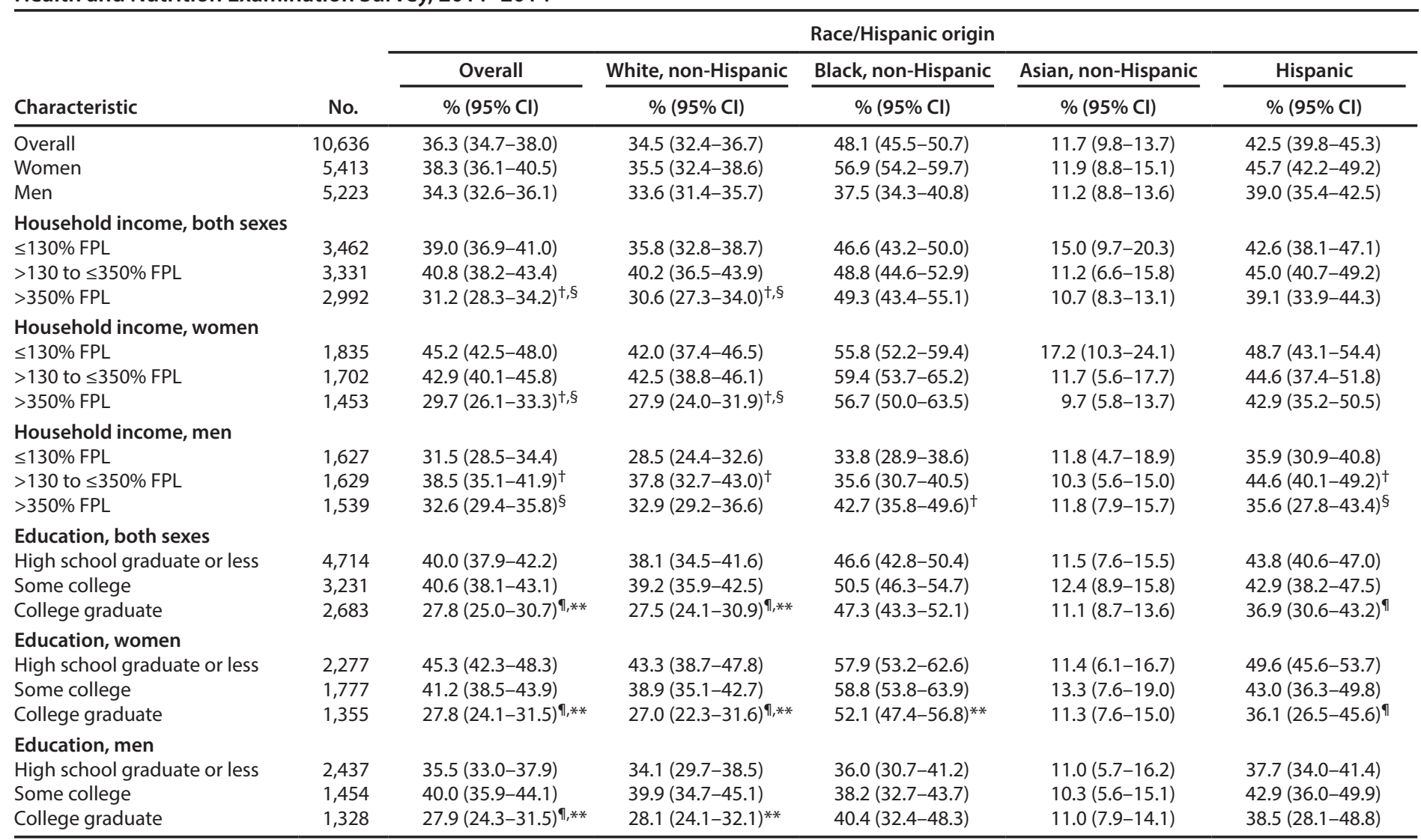

Abbreviations: $\mathrm{Cl}=$ confidence interval; $\mathrm{FPL}=$ federal poverty level.

* Age-adjusted by the direct method to the 2000 projected U.S. Census population using the age groups 20-39, 40-59, and $\geq 60$ years.

† Significantly different from $\leq 130 \% \mathrm{FPL}, \mathrm{p}<0.05$.

$\S$ Significantly different from $>130$ to $\leq 350 \% \mathrm{FPL}, \mathrm{p}<0.05$.

I Significantly different from high school graduate or less, $p<0.05$.

** Significantly different from some college, $p<0.05$.

non-Hispanic Asian women and men and Hispanic men there were no differences in obesity prevalence by education level.

From 1999-2002 to 2011-2014 the prevalence of obesity increased among women in the two lower income groups, but not among women living in households with incomes above $350 \%$ of FPL. Obesity prevalence increased among men in all three income groups during this period (Figure 1). Obesity prevalence also increased among both women and men in all education groups except men who were college graduates (Figure 2).

\section{Discussion}

During 2011-2014, the relationships between obesity and income, and obesity and education were complex, differing among population subgroups. Whereas overall obesity prevalence decreased with increased levels of income and educational attainment among women, the association was more complex among men.

Similar to results based on data from 2005-2008 (4), during 2011-2014, obesity prevalence was lower in the highest income group among women, but this was not the case among men. In fact, among non-Hispanic black men the prevalence of obesity was higher in the highest income group than in the lowest income group. Both women and men who were college graduates, on the other hand, had lower prevalences of obesity than did persons with less education.

In general, prevalence of obesity among women was lowest among college graduates, although among non-Hispanic Asians there was no difference in prevalence by level of education. This relationship was not seen when obesity was examined by income level. For example, obesity prevalence was lower in the highest income group among non-Hispanic white women, but among non-Hispanic black women, prevalence did not differ between the highest and lowest household income groups. In contrast, among both non-Hispanic black women and non-Hispanic white women, the prevalence of obesity was lower among college graduates than among women with some college. This difference in the relationship between obesity and 
FIGURE 1. Obesity prevalence among adults, by household income (percentage of FPL) and sex — National Health and Nutrition Examination Survey, 1999-2002 to 2011-2014*,

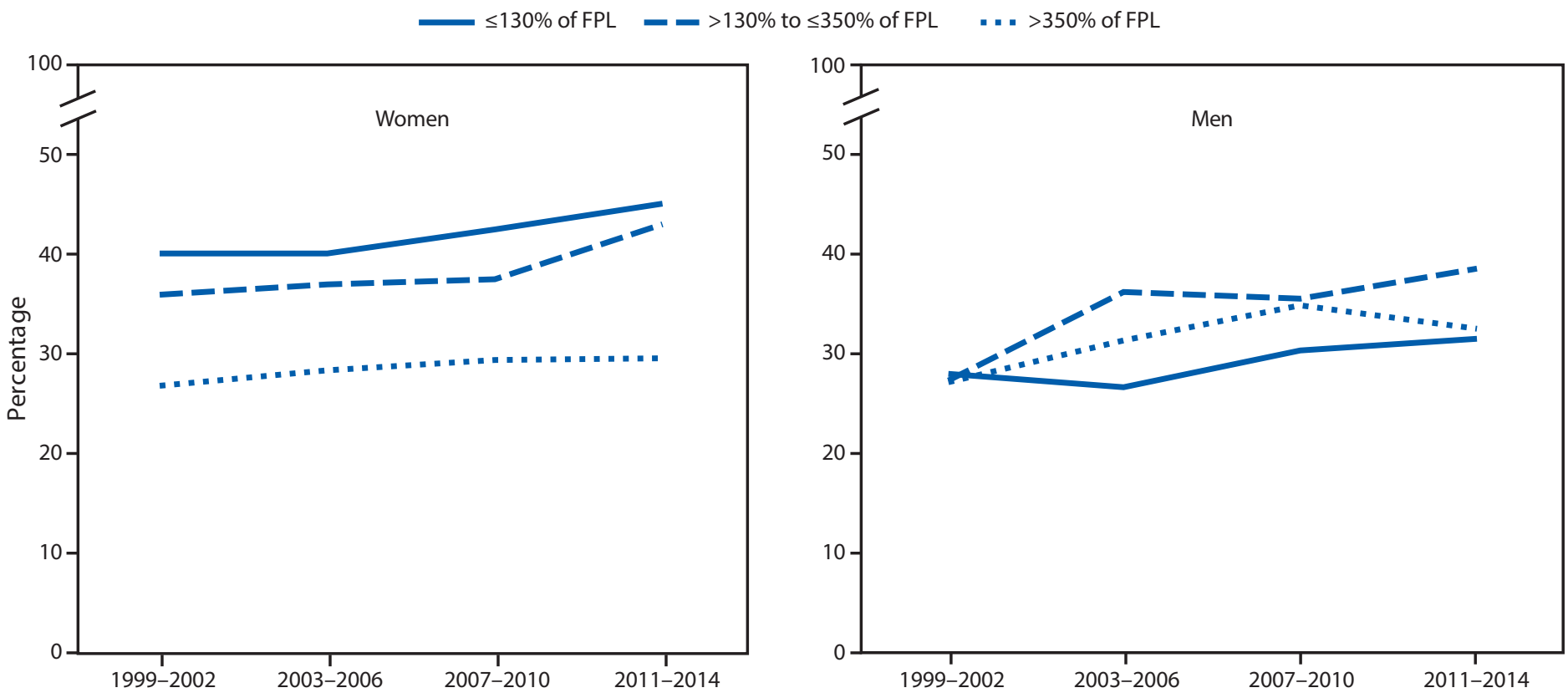

Abbreviation: $\mathrm{FPL}$ = federal poverty level.

* Estimates age-adjusted by the direct method to the 2000 projected U.S. Census population using the age groups 20-39, 40-59, and $\geq 60$ years.

† Significant linear trends for all groups except $>350 \%$ of FPL for women. For $>350 \%$ of FPL for men also significant quadratic trend. All $p<0.05$.

FIGURE 2. Obesity prevalence among adults, by education level and sex - National Health and Nutrition Examination Survey, 1999-2002 to 2011-2014*,†

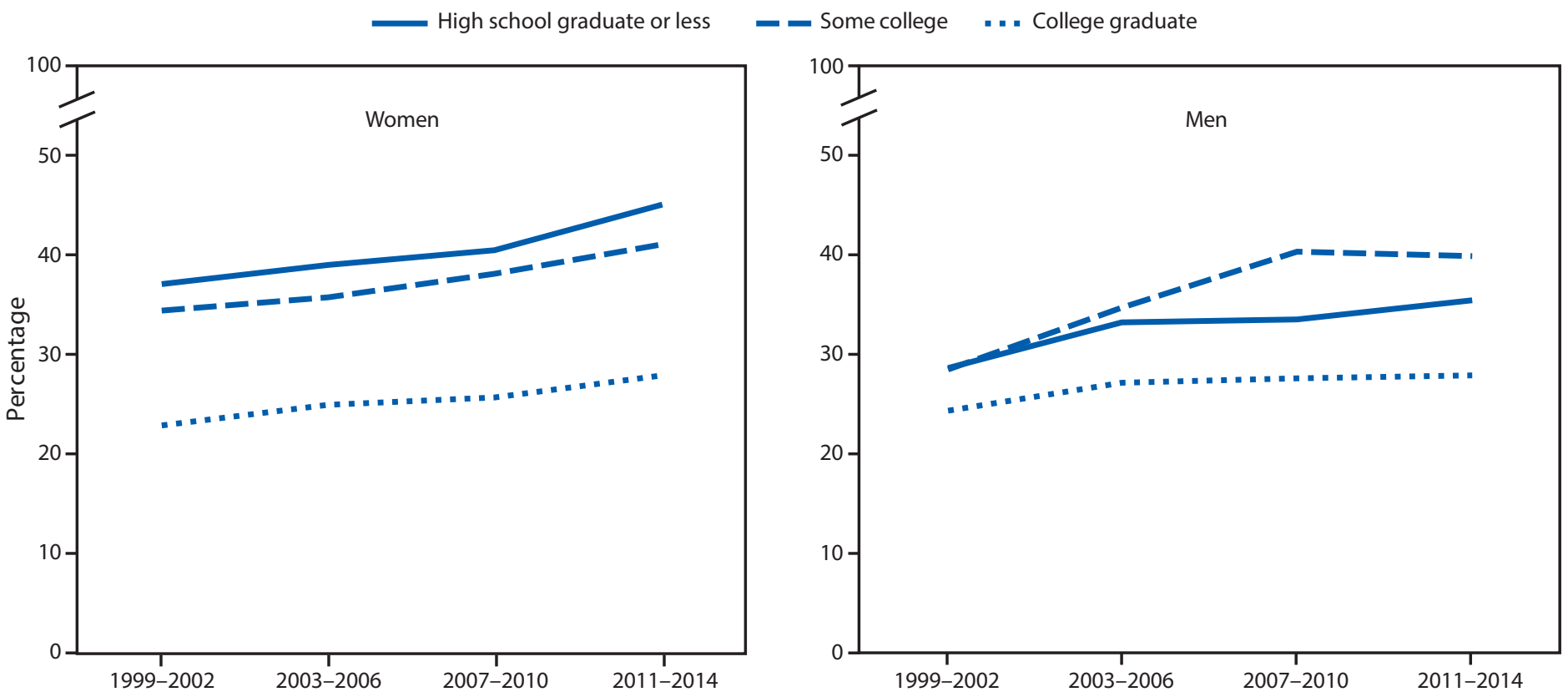

* Estimates age-adjusted by the direct method to the 2000 projected U.S. Census population using the age groups $20-39,40-59$, and $\geq 60$ years.

† Significant linear trends for all groups $(p<0.01)$ except men who were college graduates. For women college graduates $p=0.056$. 
income and obesity and education has been reported in at least one other study $(7)$ in children. These findings demonstrate that lower levels of income and education are not universally associated with obesity; the association is complex and differs by sex and race/Hispanic origin.

This is the first report to describe differences in obesity prevalence by income and education among non-Hispanic Asian adults. There were no significant differences in prevalence by income or education among either non-Hispanic Asian women or men; however, there was a pattern of decreasing prevalence with increasing income among non-Hispanic Asian women.

The findings in this report are subject to at least two limitations. First, BMI is a proxy for body fat and BMI $\geq 30$ was applied to persons in all racial/Hispanic origin groups, which might result in underestimating health risks for certain populations. For example, it has been suggested that the BMI cut point $\left(\geq 30 \mathrm{~kg} / \mathrm{m}^{2}\right)$ that typically defines obesity might be too high for Asians and underestimate associated health risks $(8,9)$. Second, the small sample size among some subgroups reduced the ability to detect differences when differences exist. Additional years of data might provide more information about obesity prevalence by income, especially among non-Hispanic Asian women.

Trends in obesity prevalence over time show that differences by income and education have existed at least since 1999-2002 among women. Among men, college graduates have consistently had a lower prevalence of obesity, whereas differences by household income have been less consistent. Further study is needed to understand the reasons for the different patterns by sex and race/Hispanic origin in the relationship between obesity and income or education.

\section{Conflict of Interest}

No conflicts of interest were reported.

${ }^{1}$ Division of Health and Nutrition Examination Surveys, National Center for
Health Statistics, CDC; ${ }^{2}$ Office of Analysis and Epidemiology, National Center
for Health Statistics, CDC; ${ }^{3}$ Divsion of Nutrition, Physical Activity and Obesity,
National Center for Chronic Disease Prevention and Health Promotion, CDC.

Corresponding author: Cynthia L. Ogden, cogden@cdc.gov, 301-458-4405.

\section{References}

1. Dinsa GD, Goryakin Y, Fumagalli E, Suhrcke M. Obesity and socioeconomic status in developing countries: a systematic review. Obes Rev 2012;13:1067-79. https://doi.org/10.1111/j.1467-789X.2012.01017.x

2. Freedman DS; CDC. Obesity-United States, 1988-2008. MMWR Suppl 2011;60:73-7.

3. May AL, Freedman D, Sherry B, Blanck HM; CDC. Obesity-United States, 1999-2010. MMWR Suppl 2013;62:120-8.

\section{Summary}

What is already known about this topic?

Studies have suggested that obesity prevalence varies by income or education, although patterns might differ in high and low income countries.

What is added by this report?

Analysis of data from the 2011-2014 National Health and Nutrition Examination Survey (NHANES) examining the association between obesity and education and obesity and income among U.S. adults demonstrate that obesity prevalence patterns by income vary between women and men and by race/ Hispanic origin. The prevalence of obesity decreased with increasing income in women (from $45.2 \%$ to $29.7 \%$ ), but there was no difference in obesity prevalence between the lowest (31.5\%) and highest (32.6\%) income groups among men. Moreover, obesity prevalence was lower among college graduates than among persons with less education for non-Hispanic white women and men, non-Hispanic black women, and Hispanic women, but not for non-Hispanic Asian women and men or non-Hispanic black or Hispanic men. The association between obesity and income or educational level is complex and differs by sex, and race/non-Hispanic origin.

What are the implications for public health practice?

NHANES will continue to be an important source of data on disparities in obesity prevalence. These data will help track the Healthy People 2020 objective of reducing obesity disparities and might inform CDC, state, or local obesity prevention programs.

4. Ogden CL, Lamb MM, Carroll MD, Flegal KM. Obesity and socioeconomic status in adults: United States, 2005-2008. NCHS Data Brief 2010-2008;2010:1-8.

5. National Center for Health Statistics. Chapter 29: nutrition and weight status. Healthy people 2020 midcourse review. Hyattsville, MD: US Department of Health and Human Services, CDC, National Center for Health Statistics; 2016. https:/www.cdc.gov/nchs/data/hpdata2020/ HP2020MCR-C29-NWS.pdf

6. National Center for Health Statistics. National Health and Nutrition Examination Survey. Hyattsville, MD: US Department of Health and Human Services, CDC, National Center for Health Statistics; 2011. https://www.cdc.gov/nchs/nhanes/index.htm

7. Lamerz A, Kuepper-Nybelen J, Wehle C, et al. Social class, parental education, and obesity prevalence in a study of six-year-old children in Germany. Int J Obes 2005;29:373-80. https://doi.org/10.1038/ sj.ijo.0802914

8. Asian Pacific Islander Health Forum. Obesityand overweightamong Asian American children and adolescents 2016. http://www.apiahf.org/resources/resources-database/ obesity-and-overweight-among-asian-american-children-and-adolescents

9. Zheng W, McLerran DF, Rolland B, et al. Association between body-mass index and risk of death in more than 1 million Asians. N Engl J Med 2011;364:719-29. https://doi.org/10.1056/NEJMoa1010679 